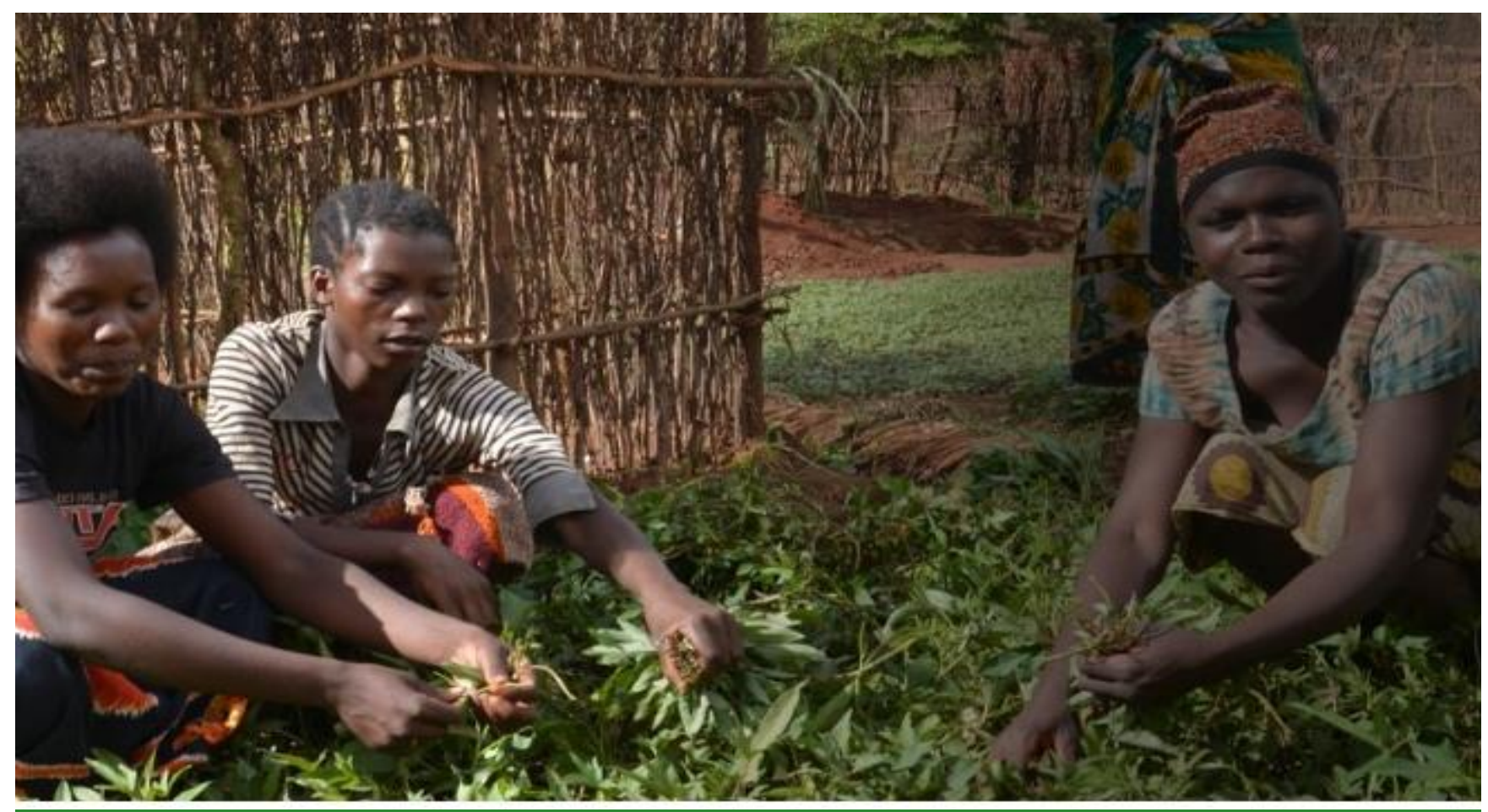

\title{
Good seed for quality produce: indigenous vegetables boost farmer incomes and livelihoods in Tanzania
}

\author{
Monica Kansiime, Jacqueline Nicodemus, Radegunda \\ Francis Kessy, Victor Afari-sefa, Damas Marandu, Silvest \\ Samali, Phil Swarbrick, Dannie Romney and Daniel Karanja
}

\section{Summary}

African indigenous vegetables (AIVs) have the potential to increase food and nutritional security and contribute to improved livelihoods, but farmers' capacity to meet the growing demand for them has been constrained by a lack of good quality seed and technical knowhow. The Good Seed Initiative (GSI), funded by Irish Aid and active in Tanzania from 2013 to 2015, targeted both seed and vegetable growers, linking them to markets through an innovation platform (IP) approach. Production and utilization of quality AIV seeds has increased in Arusha and Dodoma, and cultivation of AIVs (both seed and vegetables) has increased farmers' incomes and improved food and nutritional security for their communities. Project approaches such as farmer-to-farmer training, IPs and entrepreneurship have helped achieve sustainable linkages and improved livelihoods.

\section{Key highlights}

- 210 farmers trained in techniques for the production, processing and marketing of AIV seeds and produce, and a further 2,000 farmers trained through farmer-to-farmer extension.

- an AIV awareness campaign reached over half a million farmers, 43,000 of whom reported behaviour changes as a result. 
- increased awareness of the nutritional benefits of AIVs has boosted demand for both vegetables and seed.

- 20,000 farmers accessed and utilized quality seed, which farmers now have a steady supply of.

- an IP approach convened stakeholders in the AIV value chain to address issues and solve problems.

- communities are reporting health benefits from consuming more AIVs.

- incomes and livelihoods have improved for project participants and beneficiaries.

\section{Context}

AIVs play important roles in nutrition, food security, food diversity, rural development and sustainable land care (NRC, 2006). They are not only consumed as food but also for their preventive and curative medicinal properties (Keding et al., 2007). Awareness of the nutritional benefits of AIVs is growing amongst many East African consumers, elevating their commercial importance (Irungu et al., 2007); this has seen AIVs enter into lucrative markets resulting in better incomes for smallholder farmers. However, farmers' capacity to meet the growing demand for these vegetables has been limited by a lack of good quality seed and technical packages (Onim and Mwaniki, 2008). AIVs have not received sufficient attention from research and extension despite their potential for food and nutritional security in Africa.

Irish Aid-funded activities under the GSI programme by CABI and partners in northern and central Tanzania, aimed to partially fill this gap by improving seed systems and enhancing farmers' access to quality seeds - increasing production, productivity and farm incomes, and impacting positively on food security and economic development. CABl's work in the seed sector, over the past decade or so, has demonstrated that both supply of, and demand for seed must be addressed: even in situations where, at the outset, there is apparent unmet demand for quality seed, it can be easy to swing into a situation of oversupply. Notably, initiatives that stimulate the demand for agricultural produce from quality seed have promoted the long-term demand for those seeds. GSI project activities took that into account, looking into behaviour change in the AIV sub-sector, creating awareness of the nutritional benefits of AIVs, creating demand for them amongst farming communities, and building farmer capacity to meet that demand.

\section{What we did}

GSI reviewed all links in the AIV value chain from production and sale of seed, to vegetable growing, trade and consumption - looking to strengthen existing links and create new ones where needed.

$\mathrm{CABI}$ and partners

- Assessed training needs to develop relevant training curricula.

- Trained AIV seed and vegetable producers in good agricultural practice and linked them to extension services.

- Supported the development of farmer-led seed enterprises.

- Created, supported and improved linkages between seed producers and small- to medium-sized seed companies; and between AIV growers and traders.

- Promoted awareness of the nutritional benefits of AIVs, boosting their consumption and increasing demand for seed and produce.

Farmers were trained on soil and water management, nursery bed establishment, timely planting, water conservation, irrigation and field monitoring to establish extent of diseases/pests and to determine control measures required, and the safe application of pesticides. Seed producers were guided on post-harvest handling of seeds, contract farming and record-keeping. Vegetable growers received training on post-harvest handling, processing and marketing of vegetables. The vegetable growers went on to train others and through this farmer-to-farmer extension about 2,000 farmers received training in vegetable production. Extension workers monitored the quality of this training. 
Farmer field schools, locally known as Shamba Darasa, were established by farmer groups, and facilitated by extension workers. These demonstrations enhanced the observational learning of community members.

Seed production was organized into two distinct systems: certified seed (through contract farming) and Quality Declared Seed (QDS). Seed producers included:

- those in Dodoma in the central region who underwent training, registered with the Tanzania Seed Certification Institute (TOSCI), produced seed under the QDS system, and sold seed within their community or to agro-dealers

- contract farmers in Arusha in the north who produced seed under contract to seed companies

While contract farming provided a clear market outlet for seeds produced by farmers, QDS played a bigger role in ensuring access to quality seed for local farmers. The approach hinges on the principle of seed entrepreneurship, where seed producers are commercial entities producing seed for the purpose of selling to other farmers or other buyers.

Promotional activities such as AIV rallies, cookery shows and nutritional outreaches spread awareness of the nutritional benefits of AIVs and healthy methods of AIV preparation, especially to members of pastoralist communities, who are not typical consumers of vegetables. Radio programmes broadcasted information on AIV production, marketing and consumption. Information packs and seed packs were distributed.

The project used an IP approach whereby public and private sector stakeholders were convened to identify constraints and plan, implement and monitor actions to address them. It allowed stakeholders to share ideas and knowledge, helped farmers to secure markets for their produce and allowed contracts and partnerships to be negotiated between producers and traders.

\section{What impact was achieved?}

Impact was assessed through two sets of activities conducted in November 2015:

- a quantitative household survey that gauged the effect of promotional activities on awareness, perceptions and selection of AIVs by consumers

- a qualitative study - 15 focus group discussions (FGDs) in Arusha and Dodoma - that reviewed changes in knowledge and practices of trained seed and vegetable producers.

Information from these studies, combined with performance data and empirical evidence, demonstrates the following project impacts:

\section{Increased awareness of the benefits of AlVs}

Farming communities have an increased awareness of the benefits of AIV. Over 6,500 farmers attended rallies in Arusha and Dodoma; approximately 3,000 farmers were reached through agricultural shows and fairs; and radio shows reached approximately half a million farmers, 43,000 of whom reported behaviour change as a result of the campaigns. The impact of this is twofold: by demonstrating the economic advantages of growing AIVs over other slower-maturing, labour- and input-intensive crops, the project motivated farmers to start growing AIVs. Secondly, by increasing awareness of the nutritional benefits of AIVs, the project increased demand for AIVs, thus providing ready markets for the farmers' produce.

\section{Training and capacity-building of seed producers and vegetable growers}

- Approximately 210 farmers received on-farm training through Shamba Darasa - and were given inputs and equipment such as improved seed and solar dryers. Approximately 140 farmers were trained in seed production in Arusha; and approximately 74 farmers, including 67 women, were trained in seed and vegetable production in Dodoma. 
- Each farmer generally shared information with 10 other farmers so in total approximately 2,000 farmers were trained; $80 \%$ of farmers indicated that they understood and practiced the techniques in which they had been trained.

- A number of training and extension materials were produced (including videos and manuals on AIV production, QDS, IPs and solar drying) and are now available for use by all stakeholders.

\section{Improved quality of, and access to AIV seed}

- The quality of seeds produced by farmers improved significantly from previous years; in tests conducted in $2014,60 \%$ of AIV seeds grown by contract farmers in Arusha passed the minimum standards for germination and purity compared to less than $40 \%$ of samples tested previously.

- Utilization of quality AIV seed has increased in both Arusha and Dodoma, where over 20,000 farmers accessed and utilized quality seed as a result of project activities.

- Farmers indicated that because of training received, they are able to tell the difference between quality and poor seed.

- Vegetable producers now have easy access to quality seed from seed producers in their localities. Buying from seed producers within the community means farmers buy

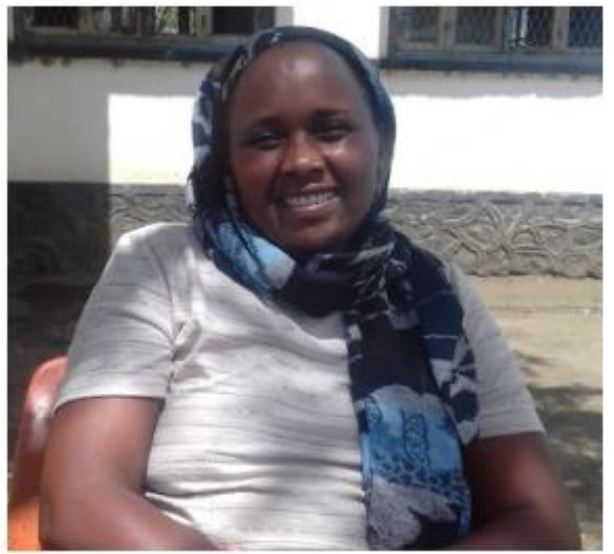

We used to grow maize, but at harvest time the prices fall, earning us small money. In addition, maize takes four months in the garden during which time I could harvest two rounds of amaranth in the same plot. We now grow maize during the long rains because we need the food, but use the second rains primarily to grow vegetables. I really thank this project for giving us training. We have really benefited from vegetable production. Each member of our group here has a story to tell, especially our women.

Mariam Mseno, a farmer in Arusha only the quantity required for a particular season or plot and therefore, have the flexibility to operate with the resources available to them at any particular time.

\section{Boosting rural incomes and livelihoods}

The training has opened farmers' eyes to AIV seed and leafy vegetable produce as an alternative income stream and they have ventured into commercial AIV seed and vegetable production. Both project elements - growing seed or vegetables - have had reciprocal benefits to villagers. Vegetable producers have access to quality seed from their seed-producing counterparts, resulting in higher yields. Similarly, seed producers have an assured market for their seed, in the form of vegetable producers.

Benefits to AIV farmers: AIVs have a number of advantages over staple crops including shorter growing cycles and lower space requirements. Farmers indicated that the short maturity period of AIVs allows them higher returns per given production area compared to traditional cash crops. For example, whereas maize is planted once in the growing season (December-June), farmers can grow 2-4 crops of AIVs within the same period. Project socio-economists have consistently found that allocating labour to AIV production is far more profitable than allocating it to traditional cash crops or hiring labour to agricultural activities (see Table 1).

Benefits to seed producers: Similarly, seed producers reported an increase in farm incomes as a result of assured markets and good prices for their seeds. Selling to seed companies means they receive lump sum payments, which allow investments in either agriculture or other areas. QDS growers have a good market for seed within their communities since vegetable growers are now aware of the benefits of quality seed. Seed growers have also secured supply agreements directly with agro-dealers, mainly in Dodoma, because of the trusted quality of their seed.

Farmers who always borrowed money for production inputs and were usually unable to recover the money invested when growing maize alone, have found that amaranth growing provides the regular income needed to run their households and are now growing maize only for household food 
requirements. Vegetable and seed sales have enabled farming families to send their children to school/college, build houses, purchase medical insurance, buy farm animals and diversify into other activities such as poultry production. The project has therefore offered farming communities alternative and lucrative income generating streams.

Table 1: Cost-benefit analysis of AIVs compared with sunflower growing in Mbori village, Mpwapwa district, Dodoma

\begin{tabular}{lccc}
\hline Variable & Sunflower (1 acre) & $\begin{array}{c}\text { Amaranth seed (1/4 } \\
\text { acre) }\end{array}$ & Amaranth leaf (1/4 acre) \\
\hline Production costs & TZS $^{*}$ & 10,000 & TZS \\
Seed & 12,000 & 80,000 & 1,500 \\
Manure & 20,000 & 10,000 & 10,000 \\
Transport & 10,000 & 10,000 & - \\
Land rental & - & 140,000 & 10,000 \\
Labour cost & 130,000 & 250,000 & 60,000 \\
Total costs & 172,000 & 26 & 81,500 \\
Labour days (no.) & 24 & 680,000 & 12 \\
Gross revenue & 420,000 & 430,000 & 360,000 \\
Gross margin & 248,000 & 21,923 & 278,500 \\
Returns per labour day & 15,750 & $1,720,000^{* *}$ & 28,208 \\
Returns per acre & 248,000 & & $1,114,000^{* * *}$ \\
\hline
\end{tabular}

* Tanzanian Shillings

** It is possible to harvest two crops of amaranth seed in one season

*** Average area under production is 1/4 acre, but farmers grow 2-3 rounds of amaranth in one season, in the same plot.

Source: FGDs with AIV seed and leafy vegetable producers (8-15 respondents).

\section{A strengthened AIV value chain}

A number of important links and connections were forged, which strengthened the entire AIV value chain:

- farmers were linked to extension services and now receive timely advice on the use of appropriate seeds and pesticides

- farmers have formed producer groups to support each other and are working together formally and informally

- four seed producing groups were linked to seed companies, resulting in the signing of production agreements and helping farmers to secure markets for their seed

- farmers were connected to the National Seed Certification Agency for inspections and quality assurance support

- links have been strengthened between vegetable growers and traders

- traders take collective orders from growers and are able to save on transport costs

- producers no longer have to walk long distances with wilting produce, and can demand higher prices for better, fresher, produce

- the use of excessive pesticides in vegetable production was raised at IP meetings and as a result, the Tanzania Food and Drugs Authority (TFDA) is developing guidelines, procedures and quality standards on vegetable processing

- one of the project partners, the World Vegetable Centre (AVRDC), has developed an online platform 'VegOneX' to facilitating efficient communication between the key players of the seed industry and efficient ordering of foundation seed; Module 2 of VegOneX provides market information to vegetable traders and consumers

- seed production agreements between farmers and seed companies are now drafted in Kiswahili, rather than English, and farmers are able to understand and implement them better 


\section{Improved food and nutritional security}

Respondents indicate that they are now:

- more aware of the nutritional and health benefits of AIVs

- growing more AIVs for their own consumption

- consuming increased quantities of AIVs and eating them more frequently

- aware that some plants that they thought were weeds could actually be consumed as vegetables and have started including them in diets

- have learnt new, more nutritious ways of preparing and preserving AIVs

In Monduli district of Arusha, 94\% of respondents say they have increased consumption of AIVs and $92 \%$ started growing their own AIVs compared to $6 \%$ before the outreach. The project has diversified food sources and increased intake of nutritious vegetables, which contributes to food and nutritional security.

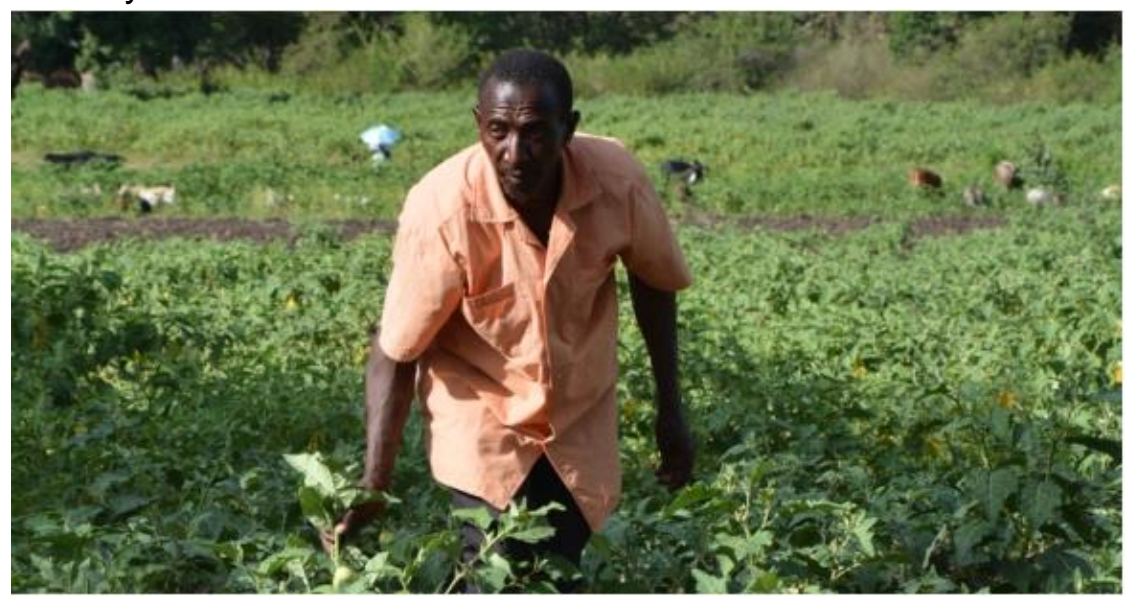

Since being involved in the GSI project Edward S. Mboya (left) and Elionora Shayo, neighbours from Kikwe village in Arusha, have rented a field together to produce vegetables and seed. They say they have benefitted greatly from the project - paying school fees for their children, building better houses and investing in side businesses such as poultry.

\section{The wider context and way forward}

GSI had a number of elements. Primarily it supported seed systems but it also promoted the nutritional benefits of AIVs and their consumption, and supported farmers to produce seed and AIVs. The project boosted consumption of AIVs, driving demand for and production of high quality seed. This provided quality seed at affordable prices for farmers, boosting the production of AIVs and the supply of vegetables for consumers. Seed producers achieved a better and consistent market for their seed. Overall income was boosted for both vegetable and seed producers. IPs creatively and efficiently brought stakeholders together to address problems.

Consolidating on these project gains, vegetable growers in project sites are now processing and drying vegetables, especially in Dodoma, to ensure a supply of vegetables during the prolonged dry spells.

GSI's work in Eastern Africa focuses mainly on the production and marketing of quality AIV seed, and fits within CABI's vision

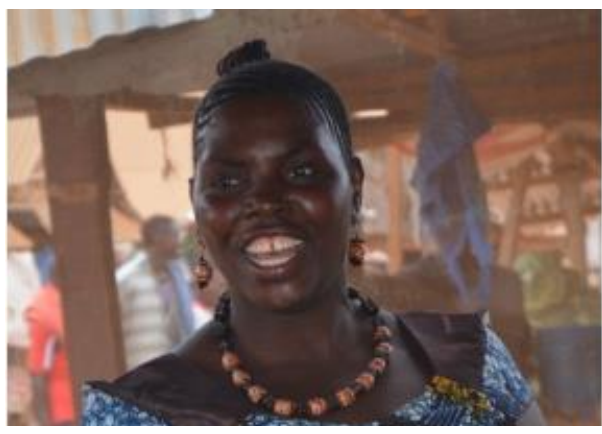

I can sell up to $500 \mathrm{k}$ of vegetables in a week. Growers sell their produce to me and I distribute to other sellers in the market. I have regular orders and if there are shortfalls of any types of vegetables

I can call farmers directly to bring more produce. I supply a church and a school with fresh vegetables.

Mapenzi Mchuzi, market trader, Kibaigwa of the world's poorest people growing more, losing less and improving their livelihoods. GSI work contributes to this vision by improving seed systems on which poor and small-scale farmers rely. Based on experiences from Tanzania, GSI commenced similar work in Uganda in 2015, focusing on AIVs. We have also been consulting with stakeholders in Zambia with the aim of scaling out project activities. 


\section{References}

Irungu, C., Mburu, J., Maundu, P., Grum, M. and Hoescle-Zeledon, I. (2007). Analysis of Markets for African Leafy Vegetables within Nairobi and its Environs and Implications for On-farm Conservation of Biodiversity. A consultancy report for Global Facilitation Unit for Underutilised Species, Rome, Italy.

Keding, G., Weinberger, K., Swai, L. and Mndiga, H. (2007). Diversity, traits and use of traditional vegetables in Tanzania; Technical Bulletin No. 40; AVRDC-The World Vegetable Center: Shanhua, Taiwan.

NRC [National Research Council] (2006). Lost Crops of Africa. Volume II: Vegetables. National Research Council of the National Academies Press: Washington, DC.

Onim, M. and Mwaniki, P. (2008). Cataloguing and evaluation of available community/farmers based seed enterprises on African indigenous vegetables (AIVs) in four ECA countries. ASARECA report, Entebbe Uganda.

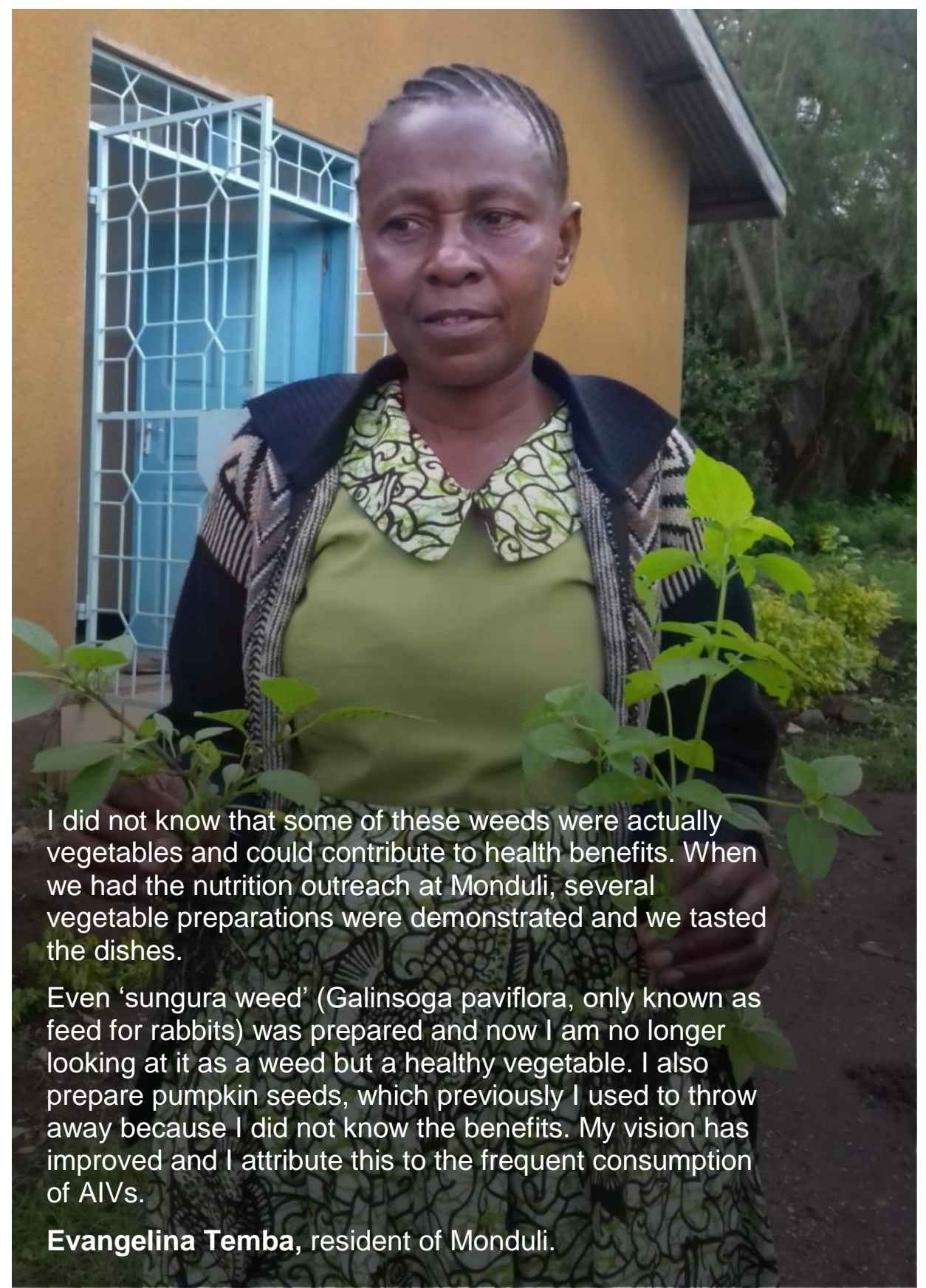





\section{Acknowledgements}

$\mathrm{CABI}$ is an international intergovernmental organisation, and we gratefully acknowledge the core financial support from our member countries (and lead agencies) including the United Kingdom (Department for International Development), China (Chinese Ministry of Agriculture), Australia (Australian Centre for International Agricultural Research), Canada (Agriculture and Agri-Food Canada), Netherlands (Directorate-General for International Cooperation), and Switzerland (Swiss Agency for Development and Cooperation).

This case study was produced as part of the activities of the project entitled "Good Seed Initiative". The project was mainly financed by Irish Aid with a small contribution from CABl's Development Fund. $\mathrm{CABI}$ was the lead institute and the project partners included: The World Vegetable Center - Eastern and Southern Africa (AVRDC-ESA); Horticultural Research and Training Institute Tengeru (HORTI Tengeru) and Inades-Formation Tanzania (IFTz) in Tanzania.

We wish to acknowledge Tan Media Communications Ltd (Radio 5), who were contracted to develop and broadcast radio programs on key topics on AIVs in Tanzania. The input from the project team members Inviolate Mosha, Hassan Mdiga, Ngoni Nenguwo, Deonice Mshinda, Ruth Chiwanga and Peter Makuya is gratefully acknowledged. The authors also thank agricultural officers from Meru, Arusha City and Arusha District Councils for their constant support during the implementation of the project activities in their areas of jurisdiction. They include Digna Masawe, Lucy Mvungi, Ashura Masumai, Agnes Maji and Halima Kiroro. The IP members including representatives from Agricultural Seed Agency (ASA), Tanzania Seed Certification Institute (TOSCl), seed companies, agro-dealers, famer groups and non-governmental organizations, among others, are gratefully acknowledged.

\section{Project donors}

Irish Aid

Rialtas na hÉireann Government of Ireland

\section{Project partners}

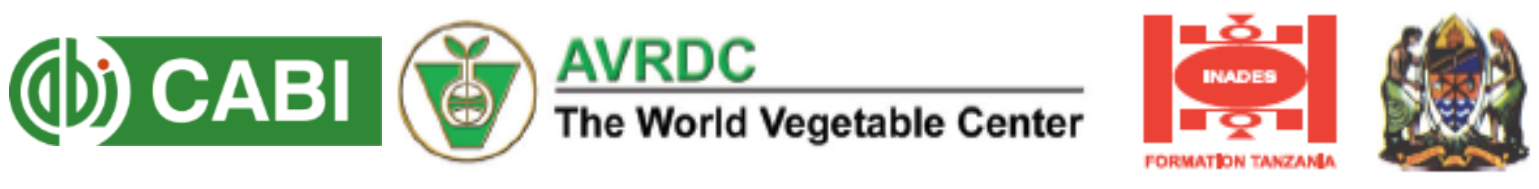

\section{Authors}

Monica Kansiime, Jacqueline Nicodemus, Radegunda Francis Kessy, Victor Afari-sefa, Damas Marandu, Silvest Samali, Phil Swarbrick, Dannie Romney and Daniel Karanja

\section{Editorial team}

Rebecca Selvarajah, WRENmedia, Technical writer

Dannie Romney, CABI, Editorial coordinator

\section{How to cite this paper}

Kansiime, M., Nicodemus, J., Kessy, R.F., Afari-sefa, V., Marandu, D., Samali, S., Swarbrick, P., Romney, D., Karanja, D. 2016. Good seed for quality produce: indigenous vegetables boost farmer incomes and livelihoods in Tanzania. CABI Study Brief 22.

DOI: http://dx.doi.org/10.1079/CABICOMM-47-495 